\title{
Langtidsprognose etter selvpåførte forgiftninger
}

\author{
Ved Mari Asphjell Bjørnaas
}

\begin{abstract}
Etter en innleggelse for selvpåført forgiftning er det kjent at dødeligheten både av selvmord og andre årsaker er økt den første tiden, men hvordan er prognosen på lengre sikt? I denne studien har vi fulgt opp alle pasienter som ble innlagt ved medisinske avdelinger i Oslo i 1980 på grunn av en selvpåført forgiftning i en 20-årsperiode etter innleggelse. Vi har undersøkt overdødeligheten blant denne gruppen, og sett på deres risikofaktorer for død og selvmord.
\end{abstract}

Blant pasienter med selvpåførte forgiftninger er det særlig to hovedgrupper: pasienter hvor forgiftningen er et resultat av selvmordsatferd, og forgiftninger som er et resultat av rus. Skillet er ofte ikke entydig. Felles for disse pasientene er en kjent overdødelighet, spesielt av selvmord. Et tidligere selvmordsfors $\varnothing \mathrm{k}$ er den sterkeste risikofaktoren for senere selvmord (Harris \& Barraclough, 1997). Både selvmordsfors $\varnothing \mathrm{k}$ og selvmord sees oftere hos opiatavhengige (Darke \& Ross, 2002) og blant alkoholmisbrukere (Hawton et al., 1989). Viktig å merke seg er også at rusmisbruk er en uavhengig risikofaktor for selvmord blant selvmordsfors $\varnothing$ kere (Hawton et al., 1993). Fellesnevneren for mange av disse pasientene er en selvdestruktiv atferd. Både rusmisbruk og intensjon bak forgiftningen bør kartlegges, og begge forhold tillegges vekt. I denne studien er pasienter innlagt for selvpåført forgiftning studert som en felles risikogruppe for tidlig død og selvmord.

Hensikten med studien har vært å unders $\varnothing$ ke d $\varnothing$ deligheten hos pasienter behandlet for selvpåf $\varnothing$ rt forgiftning i løpet av 20 år etter innleggelse, og å sammenligne dette med d $\varnothing$ deligheten i befolkningen for $\varnothing$ vrig. Vi har sett på d $\varnothing$ deligheten totalt og for ulike d $\varnothing$ dsårsaker, og sett på risikofaktorer for $\mathrm{d} \varnothing \mathrm{d}$ generelt og selvmord spesielt.

\section{Undersøkelsesmetoder}

I en tverrsnittsunders $\varnothing$ kelse i 1980 ble alle pasienter som ble behandlet for selvpåførte forgiftninger ved de fire medisinske avdelingene i Oslo inkludert i en studie (Jacobsen et al., 1984). 946 pasienter ble inkludert i en oppfølgingsstudie, seks utlendinger ble ekskludert da de ikke kunne følges i Folkeregisteret. Median alder var 31 år (13-91 år), og 51 \% var kvinner. Utvalget var uselektert og inkluderte alle selvpåførte forgiftninger fra medikamenter, alkohol og/eller illegale rusmidler, uavhengig av suicidal intensjon. Pasientene ble fulgt fram til d $\varnothing \mathrm{d}$, emigrering eller til 31.12.2000 ved hjelp av opplysninger fra Folkeregisteret. D $\varnothing \mathrm{ds}$ årsaker ble hentet fra D $\varnothing \mathrm{dsårsaksregis-}$ teret. Studien ble utført i henhold til Helsinki-deklarasjonen, og tillatelse fra Regional etisk komité og Datatilsynet forelå. Samtykke ble ikke innhentet, da dette ble vurdert å kunne $\varnothing$ ke selvmordsfaren i gruppen og dermed ikke var etisk forsvarlig. Regional etisk komité og Datatilsynet sluttet seg til denne vurderingen.

Ved hjelp av overlevelsesanalyser hvor man beregnet standard mortalitetsrate (SMR), ble utvalget sammenlignet med referanserater etter kjønn og aldersgrupper i den generelle befolkningen. SMR er ratioen mellom antall d $\varnothing$ de observert i kohorten sammenlignet med forventet antall døde dersom kohorten hadde samme rater som den generelle befolkningen. Hvis SMR er 1, betyr dette at utvalget har mortalitetsrate som forventet ut fra kjønn og alder.

Grad av suicidal intensjon ble vurdert av legen som behandlet pasienten, og var basert på all tilgjengelig informasjon, inkludert pasientens egen angivelse av hensikt og psykiatrisk vurdering der dette var blitt gjort. Det ble vektlagt om pasienten tok forholdsregler for ikke å bli funnet, inntok en letal dose eller hadde skrevet avskjedsbrev. $17 \%$ av pasientene ble vurdert som suicidale. I de resterende tilfellene var hensikten rus, eller forgiftningsepisoden ble vurdert som en appell, det vil si lav eller ingen suicidal intensjon, hvor vedkommende kontaktet andre kort tid etter inntak eller foretok andre handlinger for å unngå dødelig utgang. Et $\varnothing$ nske om å dø versus et $\varnothing$ nske om å forandre sin situasjon ble vektlagt av behandlende lege. I videre analyser ble det skilt mellom å bli vurdert som sucidial versus å ikke bli vurdert som suicidal (rusrelaterte eller appellpregede handlinger). Ikke alle pasienter hadde psykiatrisk tilsyn, og behandlende lege vurderte da intensjonen.

Klassifikasjon av rusmisbruk (daglig bruk av rusmiddel, abstinenssymptomer) ble basert på pasientens opplysninger og opplysninger i journal. Man kunne bli vurdert som suicidal og samtidig klassifisert som rusmisbruker; $45 \%$ ble klassifisert som rusmisbrukere, og av disse ble $8 \%$ vurdert som selvmordsfors $\varnothing \mathrm{k}$.

Mulige andre risikofaktorer for senere selvmord eller $\mathrm{d} \varnothing \mathrm{d}$ ble registrert ved innleggelsen, slik som bevissthet ved innkomst, lengden på sykehusoppholdet, sosioøkonomisk status, kjønn og alder. Cox regresjonsanalyser ble brukt for å unders $\varnothing \mathrm{ke}$ om disse risikofaktorene, sammen med suicidal intensjon og rusmisbruk, kunne predikere d $\varnothing$ d eller selvmord. Univariate analyser ble gjort først, fulgt av multivariate analyser som inkluderte alle variabler med $\mathrm{p}<0,15 \mathrm{i}$ de univariate analysene.

\section{Resultater}

\section{Høy d $\phi$ delighet}

I løpet av 20 år døde 355 (38 \%) av pasientene; $45 \%$ av mennene og $30 \%$ av kvinnene. Dødeligheten målt som SMR var 4,6 ganger høyere enn forventet, og var høyere enn forventet i alle 5-årsperiodene etter forgiftningsepisoden, se tabell 1 . Dødeligheten var høyest de første fem årene - SMR 6,3 - og falt til 3,3 i de siste fem årene av oppfølgingsperioden. Det var en overd $\varnothing$ delighet for alle aldersgrupper, men SMR var høyest for pasienter under 30 år ved innleggelsen.

* Denne artikkelen er et sammendrag av artikkelen Mortality and causes of death after hospital-treated self-poisoning in Oslo: A 20-year follow-up av Bjornaas, M.A., Jacobsen, D., Haldorsen, T., Ekeberg, O. Clinical Toxicology (2009) 47, 116-123. 
Tabell 1. Overdødelighet blant pasienter behandlet for selvpåførte forgiftninger i 20-årsperioden etter innleggelse.

\begin{tabular}{|l|c|c|c|c|c|c|}
\hline & \multicolumn{3}{|c|}{ Dødelighet totalt } & \multicolumn{3}{c|}{ Selvmord } \\
\hline & Døde & SMR & $95 \%$ K.I. & Selvmord & SMR & $95 \%$ K.I. \\
\hline $1980-85$ & 124 & 6,3 & $5,3-7,5$ & 29 & 36,1 & $25,1-51,9$ \\
\hline $1986-90$ & 86 & 4,5 & $3,6-5,5$ & 15 & 20,6 & $12,4-34,2$ \\
\hline $1991-95$ & 85 & 4,3 & $3,5-5,4$ & 13 & 23,4 & $13,6-40,3$ \\
\hline $1996-00$ & 60 & 3,3 & $2,5-4,2$ & 10 & 23,4 & $12,6-43,5$ \\
\hline Totalt & 355 & 4,6 & $4,2-5,1$ & 67 & 26,7 & $21,0-33,8$ \\
\hline
\end{tabular}

Tabell 2. Overdødelighet (SMR) for ulike dødsårsaker blant pasienter behandlet for selvpåførte forgiftninger i 20 år etter innleggelsen.

\begin{tabular}{|l|c|c|c|c|c|}
\hline & Antall & $\begin{array}{c}\text { Suicidal } \\
\text { intensjon* } \\
\text { i } 1980\end{array}$ & $\begin{array}{c}\text { Rusmis- } \\
\text { brukere* } \\
\text { i } 1980\end{array}$ & SMR & $95 \%$ K.I. \\
\hline Kreft & 31 & 4 & 20 & 1,5 & $1,0-2,1$ \\
\hline Hjerte/karsykdom & 70 & 10 & 35 & 2,3 & $1,8-2,9$ \\
\hline Annen sykdom & 136 & 14 & 95 & 7,5 & $6,3-8,9$ \\
\hline Ulykker & 41 & 6 & 32 & 9,3 & $6,8-12,6$ \\
\hline Selvmord & 67 & 24 & 28 & 26,7 & $20,8-33,9$ \\
\hline Annen voldsom død** & 10 & 1 & 7 & 26,7 & $14,4-49,6$ \\
\hline Totalt & 355 & 59 & 217 & 4.6 & $4,2-5,1$ \\
\hline
\end{tabular}

* Ikke alle pasienter ble klassifisert som enten rusmisbrukere eller suicidale; derfor blir summen her lavere enn det totale antall døde.

** Annen voldsom død inkluderer ytre årsak til død som ikke er selvmord eller ulykke, for eksempel vold, overfall, krigshandlinger og medisinsk feilbehandling.

Tabell 3. Selvmordsmetoder hos pasienter som tok selvmord etter at de i 1980 hadde vært innlagt på grunn av en selvpåført forgiftning.

\begin{tabular}{|l|c|c|c|}
\hline & Menn, $\mathrm{n}=31$ & Kvinner, $\mathrm{n}=36$ & Totalt, $\mathrm{n}=67$ \\
\hline Forgiftning & $16(52 \%)$ & $22(61 \%)$ & $38(57 \%)$ \\
\hline Hengning & $6(19 \%)$ & $7(19 \%)$ & $13(19 \%)$ \\
\hline Skytevåpen & $4(13 \%)$ & $2(6 \%)$ & $6(9 \%)$ \\
\hline Utsprang fra stor høyde & $2(6 \%)$ & $2(6 \%)$ & $4(6 \%)$ \\
\hline Gass & $1(3 \%)$ & $1(3 \%)$ & $2(3 \%)$ \\
\hline Kutting/skjæring & $1(3 \%)$ & $1(3 \%)$ & $2(3 \%)$ \\
\hline Uspesifisert & $1(3 \%)$ & $1(3 \%)$ & $2(3 \%)$ \\
\hline Totalt & $31(100 \%)$ & $36(100 \%)$ & $67(100 \%)$ \\
\hline
\end{tabular}

De som ble vurdert som suicidale i 1980 hadde ikke høyere d $\varnothing$ delighet enn de ikkesuicidale: SMR 3,4 (95 \% K.I., 2,6-4,3) for suicidale versus SMR 4,8 (95 \% K.I., 4,3-5,4) for ikke-suicidale. Derimot hadde rusmisbrukere signifikant høyere SMR enn ikke-rusmisbrukere: 7,3 (95 \% K.I., 6,3-8,3) versus 2,9 (95 \% K.I., 2,5-3,4). Også de som verken ble vurdert som suicidale eller rusmisbrukere hadde forh $\varnothing$ yet SMR på 2,8 (95 \% K.I., 2,3-3,5), og dødeligheten var høyere enn forventet for begge kjønn og $i$ alle aldersgrupper.

\section{Dødsårsaker}

Etter 20 år var 7,4 \% døde av hjerte/karsykdommer, 7,1 \% av selvmord, 4,3\% av ulykker, 3,3 \% av kreft, 1,1 \% av annen voldsom $\mathrm{d} \varnothing \mathrm{d}$ og 14,4 \% av andre sykdommer. Dødeligheten var høyere enn forventet for alle d $\varnothing$ dsårsaker, se tabell 2. Spesielt for unaturlige d $\varnothing$ dsårsaker var SMR h $\varnothing$ y. Selvmord var 26 ganger hyppigere forekommende i vår kohort enn i den generelle befolkningen. SMR var høyest den første perioden, se tabell 1 , men selv i den siste 5-årsperioden var SMR 23,4.

\section{Selvmordsrisiko}

I løpet av oppfølgingsperioden tok 67 pasienter livet av seg; 31 menn og 36 kvinner. SMR for menn var 17,8 (95 \% K.I., 12,5 $-25,4)$ og 46,4 for kvinner (95 \% K.I., 33,5-64,4). Det forventede antall selvmord i normalbefolkningen var 2,51,, mens det her var 67. SMR ble derfor 26,7. Det var st $\varnothing$ rst risiko for selvmord det første året, selv om risikoen var vedvarende $h \varnothing y$. Spesielt utsatt var de pasientene som ble vurdert som suicidale ved innleggelsen i 1980; her var risikoen 67 ganger høyere enn forventet, og $15 \%$ av denne undergruppen tok livet sitt i ettertid. Blant rusmisbrukere var risikoen 22 ganger høyere enn forventet. For de som verken var suicidale eller rusmisbrukere, var SMR 23.

Selvpåf $\varnothing$ rte forgiftninger var den vanligste selvmordsmetoden både blant menn og kvinner, se tabell 3. Overgang til "hardere metoder" var likevel nokså vanlig.

\section{Risikofaktorer for $\mathrm{d} \phi \mathrm{d}$}

Cox regresjonsanalyser viste at uavhengige risikofaktorer for $\mathrm{d} \varnothing \mathrm{d}$ i oppfølgingsperioden var det å være mann, tilhøre lavere sosio$\varnothing$ konomiske grupper, rusmisbruk og det å ha nedsatt bevissthet ved innleggelsen $\mathrm{i}$ 1980. Lavere bevissthet ble tolket som et uttrykk for en mer alvorlig forgiftning. Lengden av oppholdet hadde imidlertid ingen prediktiv verdi. A bli vurdert som suicidal ved innleggelsen var ikke en uavhengig risikofaktor for $\mathrm{d} \varnothing \mathrm{d}$. Risikofaktorene for $\mathrm{d} \varnothing \mathrm{d}$ var dermed svært uspesifikke, og vanskelige å bruke for å ekskludere pasienter med lavere risiko.

\section{Risikofaktorer for selvmord}

Å bli vurdert som suicidal ved innleggelsen i 1980 var den eneste uavhengige risikofaktoren for å ta sitt liv i oppfølgingsperioden. Å bli vurdert som suicidal $\varnothing$ kte risikoen for å d $\varnothing$ av selvmord 3,1 ganger (95 \% K.I., 1,8-5,7). Dette gjaldt både menn og kvinner.

\section{Hovedpoenger}

Den høye dødeligheten blant denne pasientgruppen av selvpåførte forgiftninger samsvarer med den $\varnothing \mathrm{kte}$ risikoen for tidlig død som er funnet blant selvmordsfors $\varnothing$ kere (Nordentoft et al., 1993), rusmisbrukere (Gossop et al., 1989) og opiatavhengige (Joe \& Simpson, 1987). 
I en klinisk hverdag i akuttmottaket er det derfor rasjonelt å betrakte denne pasientgruppen som en felles risikogruppe for tidlig $\mathrm{d} \varnothing \mathrm{d}$.

Et mer alvorlig forgiftningsbilde vil ofte gi nedsatt bevissthet ved innkomst, og vi fant at lavere bevissthetsnivå var en prediktor for $\mathrm{d} \varnothing \mathrm{d}$ i oppf $\varnothing$ lgingsperioden. Dette stemmer med andre studier som viser at alvorlige selvmordsfors $\varnothing \mathrm{k}$ har høyere risiko enn andre (Beautrais, 2003). Imidlertid fant vi ikke at lavere bevissthetsnivå var en prediktor for selvmord.

Selv blant forgiftningspasienter fant vi en overgang til "hardere metoder" ved senere selvmord, slik som hengning og skyting. Imidlertid var andelen som valgte selvpåført forgiftning som metode høyere både blant menn og kvinner i vår kohort enn det vi ser i den generelle befolkningen. I vår kohort hadde $61 \%$ av kvinnene og $52 \%$ av mennene brukt forgiftning som selvmordsmetode, mens i den generelle befolkningen var andelene rundt $40 \%$ og $20 \%$ i samme periode (SSB, 2009).

$\mathrm{Vi}$ fant en overd $\varnothing$ delighet av alle d $\varnothing \mathrm{ds}$ årsaker, både naturlige og unaturlige, hos pasienter innlagt for selvpåført forgiftning. Ulykker og annen voldsom d $\varnothing \mathrm{d}$ kan reflektere mennesker som lever med et rusmisbruk, hvor mange balanserer mellom liv og d $\varnothing \mathrm{d}$. Intraven $\varnothing$ st rusmisbruk er en risikofaktor for infeksjonssykdommer (Bargagli et al., 2006) og for hjerte/karsykdommer slik som endokarditt (Moreillon \& Que, 2004). Psykisk sykdom er også vist å være en risikofaktor for somatisk sykdom (Harris \& Barraclough, 1998), både på grunn av redusert hjelpesøking, bivirkninger av psykofarmaka og sannsynligvis også via ukjente mekanismer. Lav sosial klasse ble funnet å være en riskofaktor for overdødelighet, og dette er tidligere funnet for hjerte-/ karsykdom (Marmot, 1996), kreft (Woods et al., 2006) og selvmord (Hawton et al., 2001).

$\AA$ vurdere intensjon viste seg å ha prediktiv verdi for risiko for selvmord i oppfølgingsperioden. Dette er et viktig poeng å formidle tilbake til legene som behandler pasientene i akuttmottak og på medisinsk avdeling. Dette er sammenfallende med funn i andre studier.
Det er verdt å merke seg at det var $\varnothing \mathrm{kt}$ dødelighet av alle årsaker, også selvmord, selv blant de pasientene som verken ble vurdert som suicidale eller som rusmisbrukere ved innleggelsen. Dette kan være fordi deres intensjon eller rusmisbruk ikke ble riktig vurdert. Samtidig kan suicidal intensjon være vanskelig å vurdere i retrospekt, da selvmordstanker er labile. Selv handlinger som vurderes som mer appellpregede, med lav eller ingen suicidal intensjon, kan gå forut for mer alvorlige handlinger. Risikoen for $\mathrm{d} \varnothing \mathrm{d}$ og selvmord på lang sikt hos denne pasientgruppen viser et behov for mer systematisk oppfølging enn i dag, hvor særlig suicidal intensjon tillegges vekt ved henvisning videre i hjelpeapparatet (Bjornaas et al., 2010). Rusmisbruk var en risikofaktor for overdødelighet i 20-årsperioden, men til tross for dette utskrives mange av disse forgiftningene uten tilbud om oppfølging så lenge de ikke blir vurdert som suicidale. I denne studien så vi en overd $\varnothing$ delighet av alle årsaker, ikke bare rusrelaterte dødsfall. I en studie fra Oslo i 2003 ble $36 \%$ av rusrelaterte forgiftninger utskrevet uten oppfølging, ikke engang hos fastlegen (Bjornaas et al., 2010). Dette kan ikke forsvares med tanke på deres dårlige prognose på lang sikt, og tilbudet til denne pasientgruppen bør styrkes.

\section{Begrensninger}

Vurdering av intensjon ble gjort av legen som behandlet pasienten, uten at noen validert skala ble brukt. Opplysninger fra et eventuelt psykiatrisk tilsyn var tilgjengelig. Dette er slik det gjøres i klinisk praksis, både i 1980 og i dag, men mangelen på standardisering kan diskuteres.

Dødsårsaker ble hentet fra Dødsårsaksregisteret, og validiteten på disse ble vurdert som god av vår gruppe i 1985 (Ekeberg et al., 1985). Dessverre har obduksjonsfrekvensen falt dramatisk siden da, og våre tall for selvmord må betraktes som et minimum.

\section{Konklusjon}

På lang sikt har pasienter innlagt på grunn av selvpåført forgiftning $i$ akuttmottaket $\varnothing \mathrm{kt} \mathrm{d} \varnothing$ delighet sammenlignet med den generelle befolkningen. Det er $\varnothing \mathrm{kt}$ d $\varnothing$ delighet av både naturlige og unaturlige d $\varnothing$ dsårsaker, og spesielt d $\varnothing$ deligheten av selvmord er høy. Dødeligheten er vedvarende høy over en 20-årsperiode. Den høye dødeligheten b $\varnothing \mathrm{r}$ tas hensyn til ved planlegging av oppfølging etter utskrivelse fra medisinsk avdeling.

\section{Hovedbudskap}

Overdødeligheten blant selvpåførte forgiftninger var 4,6 ganger høyere enn forventet $\mathrm{i}$ løpet av 20 år etter innleggelsen i 1980.

Det var høyere dødelighet av alle årsaker blant pasientgruppen sammenlignet med den generelle befolkningen, både av naturlige og unaturlige dødsårsaker.

$7 \%$ av pasientene tok i ettertid sitt liv, og dette var 26,7 ganger høyere enn forventet.

Risikofaktorer for død per se var uspesifikke, mens en klar suicidal intensjon ved innleggelsen i 1980 var eneste uavhengige risikofaktor for selvmord i oppfølgingsperioden.

Risikoen for selvmord og død var forhøyet selv 20 år etter innleggelsen.

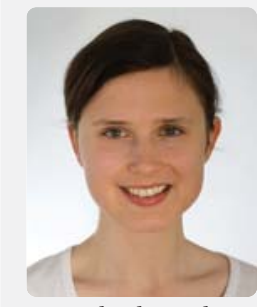

Mari Asphjell Bjørnaa er lege i spesialisering ved akuttmedisinsk av deling, Oslo Universitetssykehus, Ullevål. Hun disputerte i 2009. Avhandlingens tittel var Selupåførte forgiftninger $i$

Oslo: Epidemiologi, rusmisbruk, psykososiale faktorer og prognose. Hun deltar fortsatt i forskningsprosjekter som omhandler selvpåførte forgiftninger 


\section{Nye doktorgrader i suicidologi - NSSF gratulerer!}

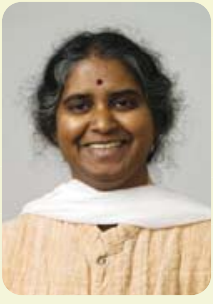

Ph.d. Latha Nrugham,

forsker ved NSSF, disputerte ved NTNU 17. desember 2010

Avhandlingens tittel: Associates and predictors of attempted suicide among depressed adolescents

- A 6-year prospective study

Tema: Selvmordsfors $\phi \mathbf{k}$ blant deprimert ungdom.

Hva skiller deprimerte ungdommer som prøver å ta sitt

eget liv, fra dem som ikke gjør det?

Nrugham har i sin avhandling studert sammenhengen mellom selvmordsfors $\varnothing \mathrm{k}$ og depresjon, og finner at kombinasjonen av spesifikke depressive symptomer og stressbelastninger som ungdommene hadde vært utsatt for, har forklaringsverdi. Risikofaktorer i hele ungdomstiden ble unders $\varnothing \mathrm{kt}$ i en undergruppe av deprimert skoleungdom som ble fulgt opp over 6 år.

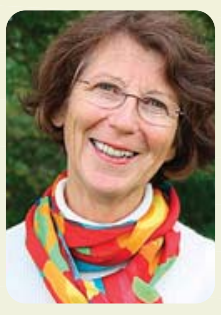

\section{Ph.d. Ildri Kjølseth}

ved RVTS Øst, disputerte ved $\mathrm{UiO} 12$. november 2010

Avhandlingens tittel: Control in life - and in death: an understanding of suicide among the elderly

\section{Tema: Selvmord hos eldre i Norge}

Målet med denne studien var å skaffe kunnskap som kan gi en forståelse av eldres selvmord i Norge. Resultatene viser en rekke fellestrekk i beskrivelsene av de eldre selvmorderne. Denne kunnskapen viser hva som kjennetegnet dem og er viktig for å kunne fange opp og hjelpe eldre i selvmordsfare.

Fellestrekkene besto i at de hadde fremstått som viljesterke, egenrådige personer og vært handlingsorienterte i uttalt grad. De var avhengige av å ha kontroll selv. Funksjonstap hadde medført tap av selvbestemmelse og handlingsrom, som for dem innebar "å miste seg selv". De opplevde at livet slik de фnsket å leve det, var over, og de opplevde livet som en byrde. De aksepterte døden og hadde gitt uttrykk for at de $\varnothing$ nsket den.

Deres forhold til helsevesenet var preget av mistro fordi de fryktet ytterligere tap av autonomi og dermed verdighet, dersom de ble avhengige av hjelp. De var derfor ofte avvisende til hjelpen fra helsevesenet. Mot slutten av livet ble mistroen bekreftet. De fikk ikke hjelp slik de ønsket det.

Studien er en psykologisk autopsistudie. 23 selvmord, 19 menn og fire kvinner i alderen 65 til 90 år, ble unders $\varnothing \mathrm{kt}$ gjennom intervjuer med personer som kjente de avdøde godt. (34 slektninger, 17 fastleger og 12 hjemmesykepleiere). Temaer i intervjuene var hvordan de eldre hadde vært som personer, livshistoriene og forhold i alderdommen.

\section{Ph.d. Elizabeth Ann Barrett}

ved TOP-studien, Oslo universitetssykehus/Universitetet i Oslo, Psykologisk institutt disputerte 13. desember 2010

Avhandlingens tittel: Suicidality in psychotic disorders; demographical, clinical, and neurocognitive correlates

\section{Ph.d. John Olav Roaldset}

ved Institutt for nevromedisin, NTNU disputerte 10. desember 2010

Avhandlingens tittel: Risk assessment of violent, suicidal and self-injurious behaviour in acute psychiatry - a bio-psycho-social approach
Forts. fra s. 5: Mari Asphjell Bjørnaas Langtidsprognose etter selvpåførte forgiftninger

Referanser

Bargagli, A.M., Hickman, M., Davoli, M., Perucci, C.A., Schifano, P., Buster, M. et al. (2006). Drugrelated mortality and its impact on adult mortality in eight European countries. Eur.J.Public Health, 16, 198-202.

Beautrais, A.L. (2003). Subsequent mortality in medically serious suicide attempts: a 5 year followup. Aust.N.Z.J.Psychiatry, 37, 595-599.

Bjornaas, M.A., Hovda, K.E., Heyerdahl, F., Skog, K., Drottning, P., Opdahl, A. et al. (2010). Suicidal intention, psychosocial factors and referral to further treatment - a one-year cross-sectional study of selfpoisonings. BMC.Psychiatry, 10, 58.

Darke, S. \& Ross, J. (2002). Suicide among heroin users: rates, risk factors and methods. Addiction, 97, 1383-1394.

Ekeberg, O., Jacobsen, D., Enger, E., Frederichsen, P., \& Holan, L. (1985). [The reliability of suicide statistics in Norway]. Tidsskr.Nor Laegeforen., 105, 123-127. Gossop, M., Green, L., Phillips, G., \& Bradley, B. (1989). Lapse, relapse and survival among opiate addicts after treatment. A prospective follow-up study. Br.J.Psychiatry, 154, 348-353.

Harris, E.C. \& Barraclough, B. (1997). Suicide as an outcome for mental disorders. A meta-analysis. Br.J.Psychiatry, 170, 205-228.

Harris, E.C. \& Barraclough, B. (1998). Excess mortality of mental disorder. Br.J.Psychiatry, 173, 11-53.

Hawton, K., Fagg, J., \& McKeown, S.P. (1989).

Alcoholism, alcohol and attempted suicide. Alcohol Alcohol, 24, 3-9.

Hawton, K., Fagg, J., Platt, S., \& Hawkins, M. (1993). Factors associated with suicide after parasuicide in young people. BMJ, 306, 1641-1644.

Hawton, K., Harriss, L., Simkin, S., Bale, E., \& Bond, A. (2001). Social class and suicidal behaviour: the associations between social class and the characteristics of deliberate self-harm patients and the treatment they are offered. Soc.Psychiatry Psychiatr. Epidemiol., 36, 437-443.

Jacobsen, D., Frederichsen, P.S., Knutsen, K.M., Sorum, Y., Talseth, T., \& Odegaard, O.R. (1984). A prospective study of 1212 cases of acute poisoning: general epidemiology. Hum. Toxicol., 3, 93-106.

Joe, G.W. \& Simpson, D. D. (1987). Mortality rates among opioid addicts in a longitudinal study. Am.J.Public Health, 77, 347-348.

Marmot, M.G. (1996). Socio-economic factors in cardiovascular disease. J.Hypertens.Suppl, 14, S201-S205. Moreillon, P. \& Que, Y.A. (2004). Infective endocarditis. Lancet, 363, 139-149.

Nordentoft, M., Breum, L., Munck, L.K., Nordestgaard, A.G., Hunding, A., \& Laursen Bjaeldager, P.A. (1993). High mortality by natural and unnatural causes: a 10 year follow up study of patients admitted to a poisoning treatment centre after suicide attempts. BMJ, 306, 1637-1641.

Statistisk Sentralbyrå - Statistikkbanken (2009). http://statbank.ssb.no/statistikkbanken/. Dødsårsaker. Lest 6. Desember 2010.

Woods, L. M., Rachet, B., \& Coleman, M.P. (2006). Origins of socio-economic inequalities in cancer survival: a review. Ann.Oncol., 17, 5-19. 